\title{
eNOS Knockout Mice with Advanced Diabetic Nephropathy Have Less Benefit from Renin-Angiotensin Blockade than from Aldosterone Receptor Antagonists
}

\author{
Tomoki Kosugi, ${ }^{* \dagger}$ Marcelo Heinig, ${ }^{*}$ \\ Takahiro Nakayama, ${ }^{*}$ Seiichi Matsuo, ${ }^{\ddagger}$ \\ and Takahiko Nakagawa* ${ }^{\star}$ \\ From the Division of Nephrology, ${ }^{*}$ University of Florida, \\ Gainesville, Florida; the Division of Renal Disease and \\ Hypertension, ${ }^{\dagger}$ University of Colorado Denver, Aurora, Colorado; \\ and the Division of Nephrology, ${ }^{\ddagger}$ Nagoya University, \\ Nagoya, Japan
}

While blockade of the renin angiotensin system (RAS) is beneficial in treating many patients with diabetic nephropathy, some patients show a poor response. We hypothesized that the poor response of RAS blockade is attributed to inability to stimulate endothelial nitric oxide. Recently, we reported that diabetic eNOS knockout (KO) mice develop advanced diabetic nephropathy similar to human disease. Here, we tested the hypothesis that blockade of the RAS would be less beneficial in this model than in diabetic wild-type mice. Both enalapril and telmisartan were less effective at reducing renal injury in diabetic eNOSKO mice compared with diabetic wild-type mice. Blood pressure was only transiently reduced by these treatments in diabetic eNOSKO mice and later returned to levels similar to that of untreated diabetic eNOSKO mice. Serum aldosterone tended to be paradoxically higher with enalapril or telmisartan in diabetic eNOSKO mice, whereas these treatments tended to lower aldosterone in diabetic wild-type mice. The pathogenic role of aldosterone was demonstrated by the evidence that spironolactone significantly reduced blood pressure and prevented renal injury. In addition, a higher dose of enalapril also failed to prevent hypertension and renal injury in diabetic eNOSKO mice. In conclusion, an impaired endothelial NO response could lessen the benefit of RAS inhibition in diabetic renal disease. Aldosterone blockade may provide superior protection in this setting. (AmJ Pathol 2010, 176:619-629; DOI: 10.2353/ajpath.2010.090578)
Strict blood glucose management, control of blood pressure, and blockade of the renin angiotensin system (RAS) are the gold standard for preventing and treating diabetic nephropathy. In particular, the benefit of angiotensinconverting enzyme inhibitor (ACEI) and angiotensin receptor blockers (ARBs) in diabetic nephropathy is well documented..$^{1-4}$ Despite the benefits of this therapy, diabetic nephropathy remains the leading cause of end stage renal disease (ESRD) and the number of patients with ESRD due to diabetes has been progressively increasing.

Some studies suggest that the renoprotective benefit of RAS blockade may partially involve an increase in endothelial nitric oxide bioavailability. ${ }^{5}$ Since impaired endothelial $\mathrm{NO}$ responses have also been reported in subjects with diabetic nephropathy, ${ }^{6-9}$ this raised the question of whether the efficacy of ACE inhibitors or ARBs could be affected in these subjects.

Recently our group and others have reported that mice lacking endothelial NO (eNOS knockout mice) are much more susceptible to diabetic nephropathy. ${ }^{10-12}$ We have previously shown that early treatment with insulin, or with strict blood pressure control, can ameliorate proteinuria, renal dysfunction, and histological injury. In contrast, lowering blood pressure with hydralazine prevents only the development of glomerular disease, but not tubulointerstitial injury in this model. ${ }^{11,13}$ We therefore examined the effect of ACE inhibitors and ARBs in this model. Given the possibility that RAS blockade works in part by stimulating endothelial $\mathrm{NO}$, we hypothesized that these treatments would not be as effective in preventing hypertension and

Supported by the Juvenile Diabetes Research Foundation and by National Institutes of Health grant DK-5212.

Accepted for publication September 30, 2009

T.N. has submitted a patent application on treating diabetic nephropathy by combining ACEls and ARB agents with agents that improve endothelial function.

Address reprint requests to Takahiko Nakagawa, M.D., Ph.D., Division of Renal Disease and Hypertension, University of Colorado Denver, C281, Aurora, CO 80045. E-mail: takahiko.nakagawa@ucdenver.edu. 
renal injury in the streptozotocin (STZ)-induced diabetic eNOSKO mice as the diabetic wild-type mice.

\section{Materials and Methods}

\section{Animals and Experimental Design}

The animal model of diabetic nephropathy we used is STZ model induced by two injections of high dose STZ. We used this model as our preliminary data shown that the two dose model results in slightly higher blood glucose levels and more advanced renal lesions of diabetic nephropathy (including Kimmelstiel Wilson nodules, mesangiolysis, tubulointerstitial injury, nephrotic proteinuria, and progressive renal failure and mortality). While STZ can cause acute tubular toxicity, this was not evident in our renal biopsies obtained at 4 to 8 weeks. Furthermore, we have previously shown that the renal lesions, including the tubulointerstitial disease, are almost completely blocked by insulin treatment, ${ }^{11,13}$ which strongly suggests that the renal lesions are secondary to the diabetic state. We do note that the Animal Model of Diabetic Complication Consortium prefer the five-dose model, but this same committee also states that insulin treatment is an effective method for distinguishing the pathogenic role of diabetes from STZ-induced renal toxicity. ${ }^{14}$

\section{Experiment I}

In the first experiment, diabetes mellitus (DM) was induced in 8-week-old male wild-type C57BL6J and C57BL/6J-Nos3tm1Unc (eNOSKO mice; Jackson Laboratory, Bar Harbor, ME) with intraperitoneal injections of STZ (100 mg/kg for 2 consecutive days). ${ }^{11}$ Four groups ( $n=10 /$ each group) of wild-type mice: 1 ) nondiabetic (DM) wild-type mice, 2) DM wild-type, 3) DM wild-type with enalapril, 4) DM wild-type with telmisartan, and six groups of eNOSKO mice:1) nondiabetic (DM) eNOSKO mice, 2) non-DM eNOSKO with enalapril, 3) non-DM eNOSKO with telmisartan, 4) DM eNOSKO, 5) DM eNOSKO with enalapril and 6) DM eNOSKO with telmisartan were examined. For these studies, enalapril (10 $\mathrm{mg} / \mathrm{kg}$ body weight/day), and telmisartan (2 mg/kg body weight/day) were given in the drinking water and started at 6 weeks. Concentrations of these compounds in drinking water were adjusted every 2 weeks along with water intake volume in each groups.

\section{Experiment II}

The next experiment was performed to evaluate the role of aldosterone in the renal injury in diabetic eNOSKO mice. In this study four groups ( $n=12$ per group) were

Table 1. General Characteristics at 10 Weeks in Wild-Type and eNOS KO Mice

\begin{tabular}{|c|c|c|c|c|c|c|}
\hline & \multicolumn{6}{|c|}{ Wild type } \\
\hline & \multicolumn{2}{|c|}{ Non-DM no treatment } & \multicolumn{4}{|c|}{ DM no treatment DM telmisartan DM enalapril } \\
\hline $\begin{array}{l}\text { Body weight }(\mathrm{g}) \\
\text { Blood sugar }(\mathrm{mg} / \mathrm{dl}) \\
\text { Systolic BP }(\mathrm{mm} \mathrm{Hg}) \\
\text { Kidney/body weight }\left(10^{-3}\right) \\
\text { Serum creatinine }(\mathrm{mg} / \mathrm{dl}) \\
\text { Serum K (mmol/L) } \\
\text { Urine albumin/creatinine }\end{array}$ & \multicolumn{2}{|c|}{$\begin{aligned} 25.3 & \pm 2.03 \\
108 & \pm 12 \\
110 & \pm 3.6 \\
5.8 & \pm 0.37 \\
0.017 & \pm 0.034 \\
4.5 & \pm 1.4 \\
0.026 & \pm 0.003\end{aligned}$} & $\begin{aligned} 19.1 & \pm 3.52^{\star} \\
293 & \pm 48^{\dagger} \\
124 & \pm 6.4^{\star} \\
9.4 & \pm 3.01 \\
0.13 & \pm 0.083 \\
4.5 & \pm 0.71 \\
0.25 & \pm 0.16^{\star}\end{aligned}$ & \multicolumn{2}{|c|}{$\begin{aligned} 20.2 & \pm 3.50 \\
282 & \pm 84^{+} \\
112 & \pm 11^{\ddagger} \\
9.4 & \pm 3.14 \\
0.032 & \pm 0.035^{\mathrm{T}} \\
4.2 & \pm 0.51 \\
0.14 & \pm 0.12\end{aligned}$} & $\begin{aligned} 22.9 & \pm 2.18 \\
270 & \pm 42^{\dagger} \\
104 & \pm 6.9^{\S} \\
7.6 & \pm 2.4 \\
0.036 & \pm 0.038^{\ddagger} \\
4.4 & \pm 1.9 \\
0.051 & \pm 0.031^{\ddagger}\end{aligned}$ \\
\hline \multicolumn{7}{|c|}{$\begin{array}{l}\text { Data are means } \pm \mathrm{SD}(n=10) \text {; BP, blood pressure. } \\
{ }^{*} P<0.05 \text { versus non-DM no treatment. } \\
{ }^{\dagger} P<0.001 \text { versus non-DM no treatment. } \\
{ }^{f} P<0.05 \text { versus DM no treatment. } \\
{ }^{\$} P<0.005 \text { versus DM no treatment. } \\
{ }^{T} P<0.01 \text { versus DM no treatment. }\end{array}$} \\
\hline & \multicolumn{6}{|c|}{ eNOS KO } \\
\hline & \multicolumn{3}{|c|}{ Non-DM } & \multicolumn{3}{|c|}{ DM } \\
\hline Body weight (g) & $\begin{array}{l}\text { No treatment } \\
26.1 \pm 2.25\end{array}$ & $\begin{array}{r}\text { Enalapril } \\
27.2 \pm 2.0\end{array}$ & $\begin{array}{c}\text { Telmisartan } \\
27.6 \pm 1.54\end{array}$ & $\begin{array}{l}\text { No treatment } \\
18.7 \pm 2.87^{*}\end{array}$ & $\begin{array}{c}\text { Enalapril } \\
17.9 \pm 0.30^{\dagger}\end{array}$ & $\begin{array}{c}\text { Telmisartan } \\
18.5 \pm 3.56^{\ddagger}\end{array}$ \\
\hline $\begin{array}{l}\text { Blood sugar }(\mathrm{mg} / \mathrm{dl}) \\
\text { Systolic BP }(\mathrm{mm} \mathrm{Hg}) \\
\text { Kidney/body weight }\left(10^{-3}\right) \\
\text { Serum creatinine }(\mathrm{mg} / \mathrm{dl}) \\
\text { Serum K (mmol/L) } \\
\text { Urine albumin/creatinine }\end{array}$ & $\begin{aligned} 112 & \pm 10 \\
142 & \pm 3.8 \\
5.3 & \pm 0.79 \\
0.055 & \pm 0.042 \\
4.8 & \pm 0.77 \\
0.12 & \pm 0.054\end{aligned}$ & $\begin{aligned} 108 & \pm 12 \\
116 & \pm 6.1^{*} \\
5.0 & \pm 0.61 \\
0.13 & \pm 0.090 \\
5.2 & \pm 0.53 \\
0.072 & \pm 0.017\end{aligned}$ & $\begin{aligned} 104 & \pm 14 \\
112 & \pm 8.3^{*} \\
5.3 & \pm 0.86 \\
0.10 & \pm 0.099 \\
4.6 & \pm 1.3 \\
0.04 & \pm 0.019\end{aligned}$ & $\begin{aligned} 276 & \pm 26^{\star} \\
152 & \pm 8.8 \\
10.3 & \pm 2.19^{\star} \\
0.18 & \pm 0.13 \\
4.2 & \pm 1.1 \\
2.3 & \pm 2.3^{\pi}\end{aligned}$ & $\begin{aligned} 281 & \pm 49^{\dagger} \\
148 & \pm 9.9^{\dagger} \\
9.3 & \pm 1.32^{\dagger} \\
0.18 & \pm 0.076 \\
4.2 & \pm 1.0 \\
1.4 & \pm 0.89\end{aligned}$ & $\begin{aligned} 270 & \pm 37^{\ddagger} \\
138 & \pm 13^{\ddagger \S} \\
9.4 & \pm 2.91^{\ddagger} \\
0.17 & \pm 0.14 \\
3.9 & \pm 0.33 \\
0.71 & \pm 0.47\end{aligned}$ \\
\hline
\end{tabular}

Data are means \pm SD $(n=10)$; BP, blood pressure.

${ }^{\star} P<0.001$ versus non-DM no treatment.

${ }^{\dagger} P<0.001$ versus non-DM enalapril.

$\neq P<0.001$ versus non-DM telmisartan.

$\S P<0.05$ versus DM no treatment.

TP $<0.005$ versus non-DM no treatment. 
studied, including 1) DM wild-type, 2) DM wild-type with spironolactone, 3) DM eNOSKO, and 4) DM eNOSKO with spironolactone. Spironolactone (50 mg/kg BW/day) was given in the drinking water in which $0.1 \%$ ethanol was required to dissolve spironolactone, whereas nonspironolactone groups were also treated with $0.1 \%$ ethanol in drinking water.

\section{Experiment III}

To test if higher dose of enalapril can prevent renal injury in this model, a total of three groups ( $n=5$ /each group) were studied, including 1) DM eNOSKO, 2) DM eNOSKO with enalapril, and 3) DM eNOSKO with hydralazine. Both enalapril and hydralazine treatments started at 6 weeks after induction of diabetes mellitus. Dose of enalapril was increased in a stepwise fashion from $10 \mathrm{mg}$ to $50 \mathrm{mg} / \mathrm{kg} /$ day during 16 weeks. Hydralazine (80 mg/kg/day) was used as positive control ${ }^{13}$ to compare to enalapril in effects of blood pressure and renal injury. Mice were sacrificed on 14 weeks after treatment.

For all studies, mice were confirmed to be diabetic (defined as fasting blood glucose $>200 \mathrm{mg} / \mathrm{dl}$ ) with levels measured at 1 week, 6 weeks, and 10 weeks after STZ injection. Systolic blood pressure was assessed using a tail cuff sphygmomanometer (Visitech BP2000; Visitech Systems, Apex, NC) after preconditioning. At 10 weeks mice were sacrificed under light anesthesia after blood and urine from the bladder were collected. Urinary albumin-to-creatinine ratio was measured as described previously. ${ }^{11}$ Serum potassium $\left(\mathrm{K}^{+}\right)$was measured by using an autoanalyzer (VetAce, Alfa Wassermann, West Caldwell, $\mathrm{NJ}$ ) while creatinine was measured with a commercial kit (BioQuant, San Diego, CA). All animal experiments were performed in accordance with the Animal Care and Use Committee of the University of Florida.

\section{Renal Histology}

Kidneys were fixed in Fekete's fixative, embedded in paraffin and cut into 2- $\mu \mathrm{m}$ sections for periodic acid-Schiff (PAS) staining and immunohistochemistry. ${ }^{11} \mathrm{~A}$ polyclonal rabbit anti-mouse collagen IV antibody (Chemicon International, Temecula, CA), a polyclonal rabbit anti-human fibronectin antibody (Sigma-Aldrich, St. Louis, MO), a polyclonal rabbit anti-mouse osteopontin antibody (Cosmo Bio Co., Ltd, Tokyo, Japan), a polyclonal goat anti-human collagen III antibody (Southern Biotechnology Associates, Birmingham, $\mathrm{AL}$ ) and a polyclonal goat anti angiotensin II antibody (Santa Cruz biotechnology, Santa Cruz, CA) were used for immunohistochemistry. Color was developed using 3,3'-diaminobenzidine (Dako, Carpinteria, CA). Negative controls were performed by the replacement of primary antibodies with species-matched normal serum. To document specificity for angiotensin II staining, an excess amount of angiotensin II (Sigma-Aldrich) was pre-incubated with anti-angiotensin II antibody overnight at $4^{\circ} \mathrm{C}$ before using applying in immunohistochemistry. Quantification of immunostaining was performed in cortical fields, using the AxioVision image analysis computer program (Carl Zeiss,
Thornwood, NY) in a blinded fashion and confirmed by two independent observers.

\section{Morphological Assessment}

For each biopsy 100 glomeruli from both right and left kidneys were examined. The extent of the mesangial expansion was quantified by assessing the PAS-positive and nuclei-free area in the mesangium, as previously described..$^{11}$ The glomerular area was traced along the outline of the glomerular tuft using the AxioVision image analyzer. The degree of mesangiolysis was calculated as the number of glomeruli with mesangiolysis (dissolution of the mesangial matrix) divided by that of total glomeruli.

For analysis of the tubulointerstitium, the percentage of atrophic tubules (ie, tubular dilation, detachment of tubular epithelial cells and condensation of tubular nuclei) was assessed by scoring 400 profiles of renal cortical tubules in randomly selected fields of each biopsy, as

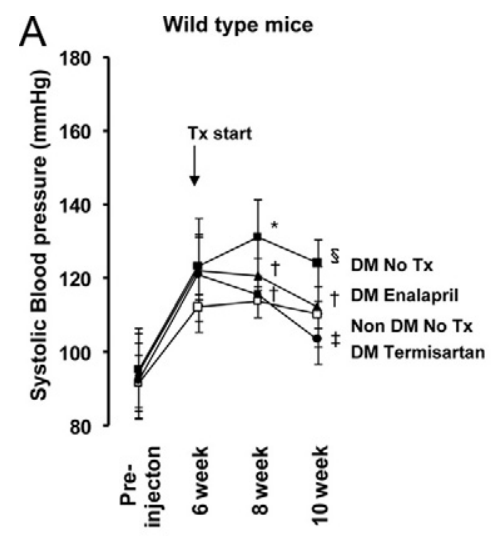

$\mathrm{B}$
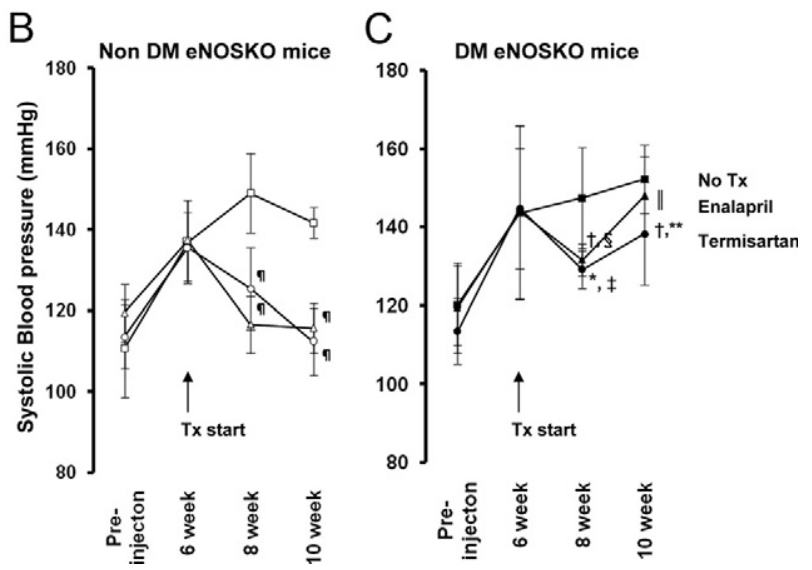

Figure 1. Time course of blood pressure in wild-type and eNOSKO mice. Enalapril or telmisartan treatment started at 6 weeks after induction of diabetes mellitus (DM). In wild-type (A) and nondiabetic eNOSKO mice (B), these treatments significantly reduced blood pressure at 8 and 10 weeks. Whereas these treatments were effective at 8 weeks in diabetic eNOSKO mice $(\mathbf{C})$, the benefit of enalapril on blood pressure was lost at 10 weeks. White square, non-DM no treatment (Tx); white triangle, non-DM enalapril; white circle non-DM telmisartan; black square, DM no Tx; black triangle, DM enalapril; black circle, DM telmisartan. Data are shown as means and SD; ${ }^{*} P<0.005$ versus non-DM non-treatment; ${ }^{\dagger} P<0.05$ versus DM non-treatment; ${ }^{\ddagger} P<$ 0.005 versus DM non-treatment; ${ }^{\circledR} P<0.05$ versus non-DM non-treatment; ${ }^{\pi} P<$ 0.001 versus non-DM non-treatment; ${ } P<0.001$ versus non-DM enalapril; ${ }_{* *}^{*} P<0.001$ versus non-DM telmisartan. $n=10$ /each group. 
previous described. ${ }^{15}$ All quantification was performed in a blinded manner by two independent investigators.

\section{Real-Time Polymerase Chain Reaction}

The mRNA extraction and cDNA synthesis were performed by using an RNeasy Mini kit and QuantiTect reverse tran- scription kit (Qiagen Science, Valencia, CA). ${ }^{16}$ Real-time polymerase chain reaction was performed with renal cortex as described previously. ${ }^{11}$ The primers were designed as following: angiotensinogen: forward 5'-GGCCGCCGAGAAGCTAGA-3', reverse 5'-GGCTGGCCGTGGGATCTA-3'; renin: forward 5'-GCCGCCTCTACCTTGCTTGTG-3', reverse 5'-GGGGCAGCTCGGTGACCTCT-3'.


\section{Mesangial expansion (\%)}

Wild type mice

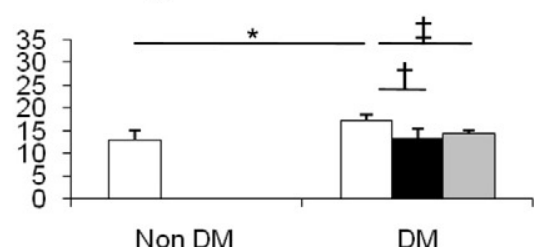

$\mathrm{N}$ Collagen IV deposition (\%)

Wild type mice

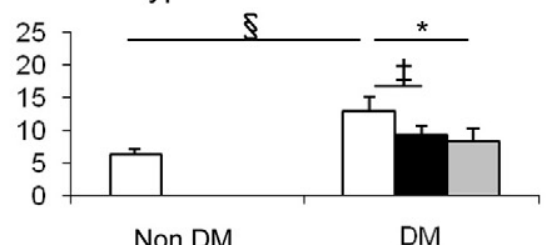

O Fibronectin deposition (\%) Wild type mice

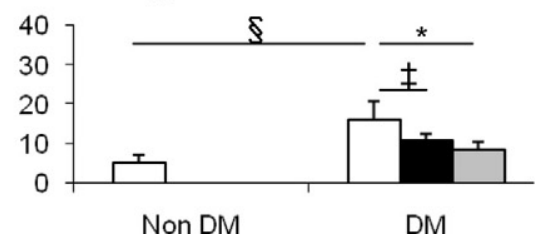

eNOSKO mice

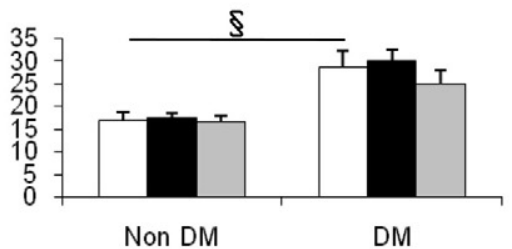

eNOSKO mice

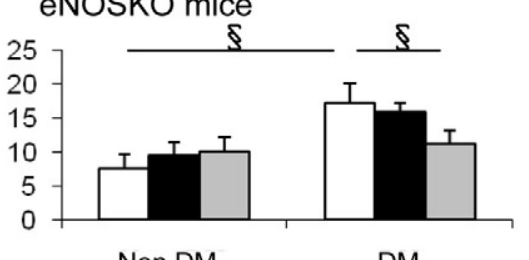

Non DM

DM

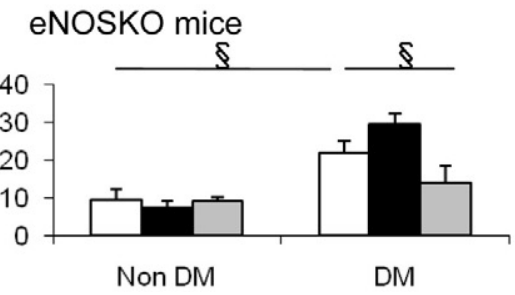

Figure 2. Glomerular lesions in wild-type and eNOSKO mice. PAS staining demonstrates normal glomerular appearance in non-DM eNOSKO mice (A). DM caused mesangial expansion in DM eNOSKO mice (B), which was not prevented by enalapril $(\mathbf{C})$ or telmisartan $(\mathbf{D})$. DM eNOSKO mice also exhibited mesangiolysis with glomerular capillary microaneurysms (E) and with augmented deposition of extracellular matrix (F). Neither enalapril (G) nor telmisartan $(\mathbf{H})$ treatment prevented these advanced lesions Scale bar $=20 \mu \mathrm{m}$. In immunohistochemistry, glomerular collagen IV deposition (brown) in non-DM eNOSKO mice is shown in (I). Compatible with the PAS findings, glomerular collagen IV deposition was markedly increased in glomerulus of DM eNOSKO mice ( $\mathbf{J}$ ), and was not prevented by enalapril $(\mathbf{K})$. In contrast, telmisartan reduced it (L). Quantitative analysis for mesangial expansion (M), glomerular collagen IV $(\mathbf{N})$, and glomerular fibronectin $(\mathbf{O})$ are shown Scale bar $=20 \mu \mathrm{m}$. White bar, no treatment black bar, enalapril; gray bar, telmisartan. Data are shown as means and SD. ${ }^{*} P<0.01 ;{ }^{\dagger} P<$ 0.005; ${ }^{\ddagger} P<0.05 ;{ }^{\mathbb{S}} P<0.001 . n=10$ /each group. 


\section{Western Blot Analysis}

Whole mouse kidney tissues were snap-frozen in liquid nitrogen. Briefly, protein samples were resolved on Tris$\mathrm{HCl}$ Ready-To-Gel (Bio-Rad Life Science, Hercules, CA) and transferred to polyvinylidene difluoride membranes by electroblotting as previously described. ${ }^{13}$ The blots were subsequently incubated with a polyclonal goat anti angiotensin II antibody (Santa Cruz Biotechnology), a polyclonal goat anti-mouse renin-1 antibody (R\&D Systems, Minneapolis, MN), a monoclonal mouse anti-mouse ACE antibody (Chemicon International, Temecula, CA), a polyclonal goat anti-mouse ACE2 antibody (Santa Cruz biotechnology), a polyclonal rabbit anti-mouse AT1R antibody (Santa Cruz biotechnology), a polyclonal rabbit anti-mouse mineralocorticoid receptor antibody (Santa Cruz Biotechnology) or monoclonal mouse anti-mouse $\beta$-actin antibody (Sigma-Aldrich), followed by incubation with peroxidase-conjugated goat IgG, rabbit IgG, or mouse IgG (DakoCytomation, Carpinteria, CA). Proteins were visualized with an enhanced chemiluminescence detection system (Amersham Pharmacia, Piscataway, NJ). The density of each band was measured using the public domain NIH Image program.

\section{ACE Activity Assay and Serum Aldosterone Measurement}

Serum ACE activity was measured using a commercial kit (Life laboratory Co., Yamagata, Japan). Serum aldosterone levels were measured using an EIA kit (Cayman Chemical, Ann Arbor, MI).

\section{Statistical Analysis}

All values are expressed as means \pm SD. Statistical analysis was performed with analysis of variance using
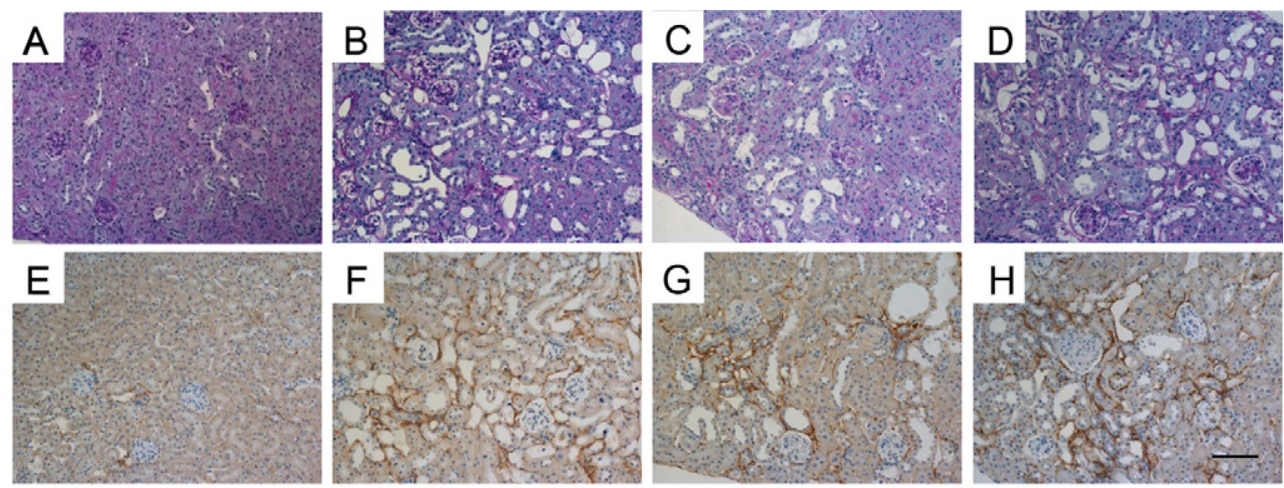

\section{Tubular damage (\%)}

\section{Wild type mice}

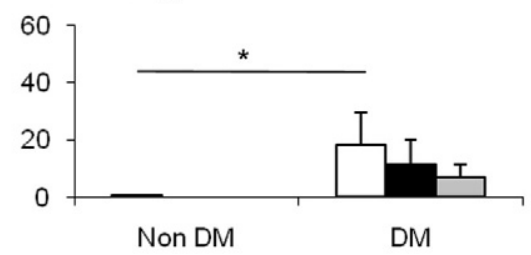

\section{J Osteopontin expression (\%)}

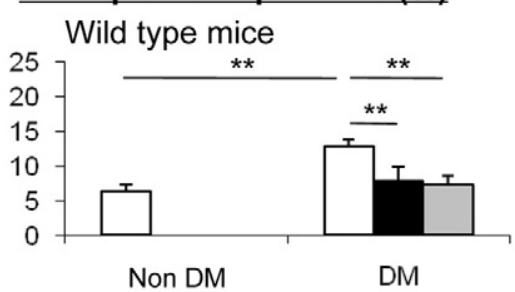

K Collagen III deposition (\%) Wild type mice

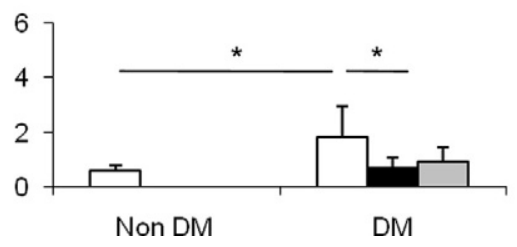

eNOSKO mice

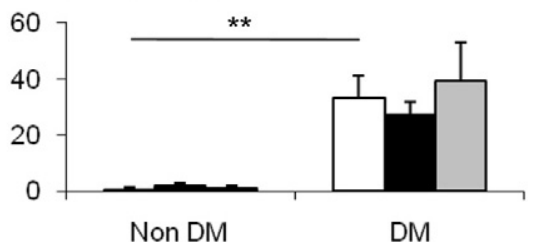

eNOSKO mice



eNOSKO mice

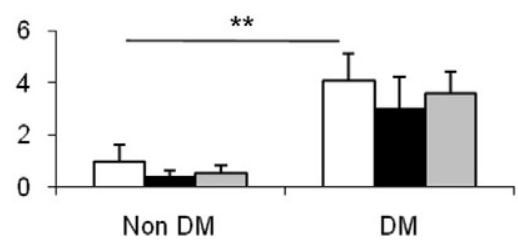

Figure 3. Tubulointerstitial lesions in wild-type and eNOSKO mice. PAS staining (A-D) and immunohistochemistry for collagen III $(\mathbf{E}-\mathbf{H})$ in renal cortex are shown. Compared with non-DM eNOSKO mice (A), DM eNOSKO mice (B) show more injury in the cortical tubulointerstitium, as evidenced by tubular dilatation and the detachment of epithelial cells within tubules. These lesions were not improved by both enalapril (C) and telmisartan (D). Interstitial collagen III deposition is shown in brown. Compared with non-DM eNOSKO (E), DM induced interstitial collagen III deposition (F). However, neither enalapril (G) nor telmisartan (H) blocked this response. Scale bar $=50 \mu \mathrm{m}$. Quantitative analysis for tubular damage (I), tubular osteopontin expression (J) and interstitial collagen III deposition $(\mathbf{K})$ are shown. White bar, no treatment black bar, enalapril; gray bar, telmisartan. Data are shown as means and SD. ${ }^{*} P<0.05 ;{ }^{* *} P<$ 0.001. $n=10$ /each group. 
Tukey's method for multiple comparisons. A $P$ value of $<0.05$ was taken to indicate a significant difference.

\section{Results}

\section{Effect of ACEl or ARB Treatment in Diabetic Wild-Type Mice and eNOSKO Mice}

Both wild-type and eNOSKO mice were made diabetic and 6 weeks later were treated with an ACEI (enalapril) or ARB (telmisartan) or continued as a control for an additional 4 weeks. This design was selected as ACE inhibitor treatment is usually not started when subjects first become diabetic. As shown in Table 1, STZ induced equivalents levels of hyperglycemia in both wild-type and eNOSKO diabetic mice, indicating the development of diabetes. While diabetes caused body weight loss and renal hypertrophy, neither enalapril nor telmisartan significantly blocked this response in either group of mice.

Renal function, measured by serum creatinine, was impaired in diabetic wild-type mice and this impairment was prevented by both ACEI and ARB treatment. In contrast, in diabetic eNOSKO mice neither ACEI nor ARB could prevent the increase in serum creatinine. Albuminuria was mild in diabetic wild-type mice and was reduced approximately $50 \%$ by ACEI (although not significantly) and to a greater extent by an ARB $(P<0.05)$. In diabetic eNOSKO mice albuminuria was significantly higher. RAS blockade tended to lower urinary albumin excretion in
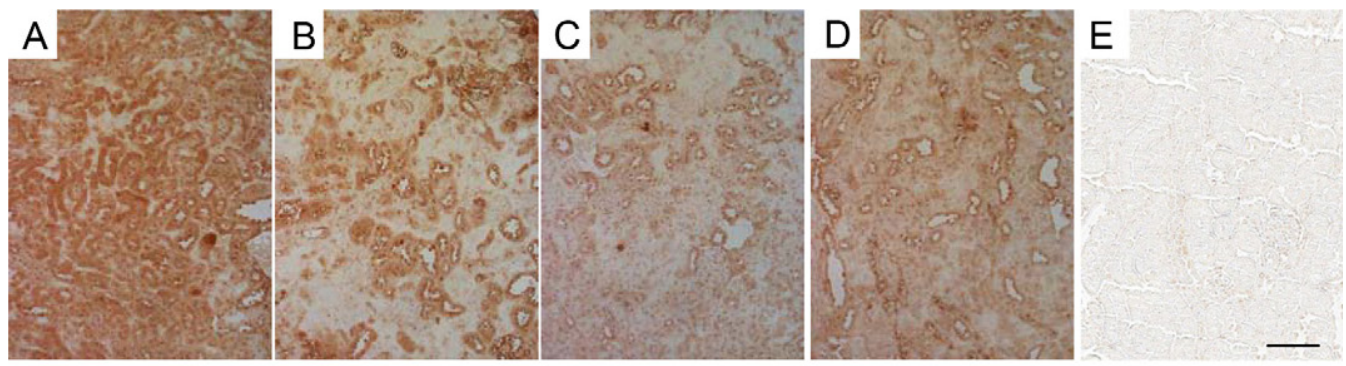

$\mathrm{F}$

Angiotensin II

ACE

ACE 2

AT1R

MCR

$\beta$-Actin
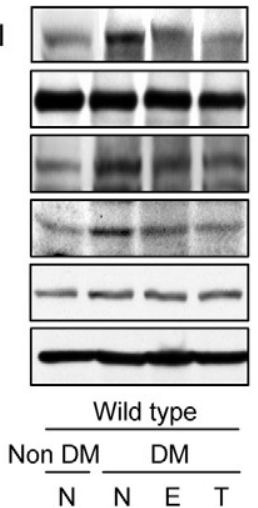

\section{G Serum ACE activity (unit/ml)} Wild type mice

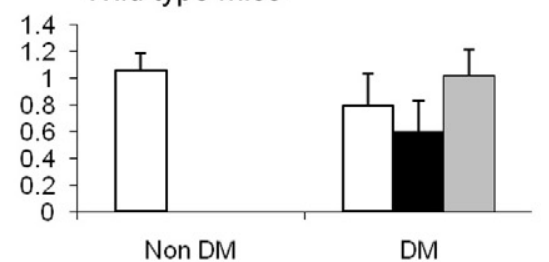

$\mathrm{H}$ Serum Aldosterone level (pg/ml)

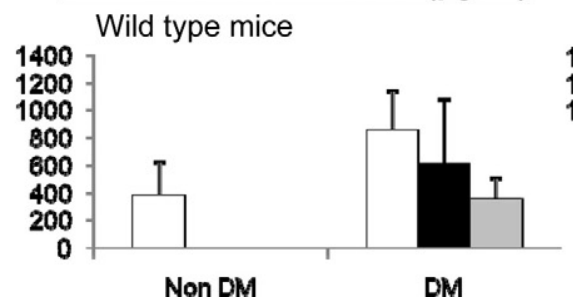

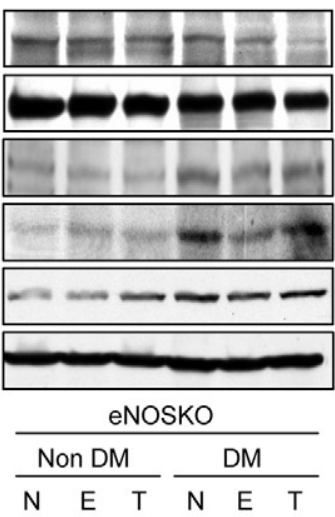

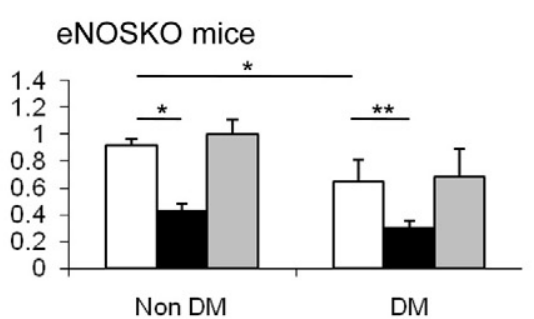

eNOSKO mice

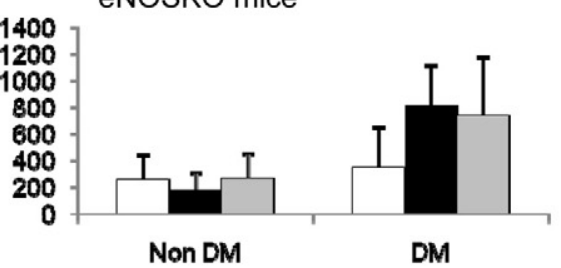

$60 \mathrm{kDa}$

$190 \mathrm{kDa}$

$90 \mathrm{kDa}$

$43 \mathrm{kDa}$

$102 \mathrm{kDa}$

$42 \mathrm{kDa}$

DM

DM
Figure 4. Renin-angiotensin-aldosterone system in wild-type and eNOSKO mice. Immunohistochemistry for angiotensin II (brown) is shown in A-E (Scale bar $=50 \mu \mathrm{m})$. Compared with DM wild-type mice (A), intrarenal angiotensin II expression was reduced in DM eNOSKO mice (B). This level of angiotensin II remained low despite enalapril (C) and telmisartan treatment (D) in DM eNOSKO mice. In absorption test, the angiotensin II immunoreactivity is completely abolished by preincubation with an excess amount of immunizing peptide (E). Western blotting for angiotensin II, ACE, ACE2, AT1R, and mineralocorticoid receptor was shown $(\mathbf{F})$. $\mathrm{N}$, no treatment; E, enalapril; T, telmisartan. In G serum ACE activity tended to be reduced by enalapril treatment in diabetic wild-type mice compared with untreated or mice receiving telmisartan of diabetic wild-type mice. In both nondiabetic and diabetic eNOSKO mice, enalapril significantly reduced serum ACE activity compared with non-treated or telmisartan-treated group. In terms of serum aldosterone concentration, both enalapril and telmisartan tended to lower it in DM wild-type mice (H). In contrast, serum aldosterone level tended to increase in DM eNOSKO mice receiving enalapril and telmisartan although this did not reach statistical difference. White bar, no treatment; black bar, enalapril; gray bar, telmisartan. Data are shown as mean $\pm \mathrm{SD} \cdot{ }^{*} P<0.001 ;{ }^{* *} P<0.005 . n=$ 10/each group. 
this model but neither treatment reached significance (Table 1). Serum potassium was not different in any of the groups.

\section{Blood Pressure in Diabetic Wild-Type and eNOSKO Mice}

As shown in Figure $1 \mathrm{~A}$, diabetes resulted in an elevation in blood pressure in the wild-type mice at 8 and 10 weeks, which was significantly reduced by either enalapril or telmisartan. In nondiabetic eNOSKO mice, blood pressure was also significantly lowered by these treatments at 8 and 10 weeks (Figure 1B). In contrast, in diabetic eNOSKO mice, treatments with an ACEl resulted in a transient decrease in blood pressure at 8 weeks (Figure 1C), and blood pressure returned to higher levels at 10 weeks despite continued enalapril treatment. Similarly, telmisartan reduced blood pressure slightly but significantly in diabetic eNOSKO mice compared with non-treated diabetic eNOSKO mice at 10 weeks. Blood pressure was more effectively lowered by telmisartan at 8 weeks as similar to enalapril.

\section{Glomerular Injury in Diabetic Wild-Type and eNOSKO Mice}

In wild-type mice, diabetes caused mesangial expansion and increased collagen IV and fibronectin depositions, all of which were blocked by enalapril and telmisartan treat- ment (Figure 2, A-O). Diabetic eNOSKO mice also developed glomerular injury. However, in contrast to diabetic wild-type mice, enalapril did not block the glomerular injury, while telmisartan partially prevented collagen IV and fibronectin deposition in diabetic eNOSKO mice (Figure 2). Mesangiolysis (as advanced lesion) was also induced in diabetic eNOSKO mice $(2.6 \pm 1.7 \%$ in nondiabetic eNOSKO versus $14.3 \pm 6.4 \%$ in diabetic eNOSKO, $P<$ $0.01)$ but was not prevented by either treatment $(18.0 \pm$ $6.8 \%$ in diabetic eNOSKO with enalapril, $12.9 \pm 5.2 \%$ with telmisartan, $P=\mathrm{NS}$ ).

\section{Tubulointerstitial Injury in Diabetic Wild-Type and eNOSKO Mice}

As shown in Figure 3, A-I, tubulointerstitial injury was mild in diabetic wild-type mice but was more severe in diabetic eNOSKO mice. We have previously reported that the tubulointerstitial injury observed in diabetic eNOSKO mice can be largely prevented with insulin treatment, suggesting that the injury could be secondary to diabetes. ${ }^{13}$ In diabetic wild-type mice, these lesions were significantly prevented by enalapril and telmisartan while they were not prevented in diabetic eNOSKO mice. Consistently, tubular osteopontin expression (a marker of damaged tubules) and interstitial collagen III deposition were reduced by enalapril and telmisartan in wild-type mice but not eNOSKO mice (Figure $3, \mathrm{~J}$ and $\mathrm{K}$ ).

Table 2. Renin-Angiotensin-Aldosterone System in Wild-Type and eNOS KO Mice

\begin{tabular}{|c|c|c|c|c|c|c|}
\hline & \multicolumn{6}{|c|}{ Wild type } \\
\hline & \multicolumn{2}{|c|}{ Non-DM } & \multicolumn{4}{|c|}{ DM } \\
\hline & \multicolumn{2}{|c|}{$\overline{\text { No treatment }}$} & No treatment & \multicolumn{2}{|c|}{ Enalapril } & Telmisartan \\
\hline Angiotensinogen mRNA & \multicolumn{2}{|c|}{$1.99 \pm 0.91$} & $3.36 \pm 1.67$ & \multicolumn{2}{|c|}{$3.72 \pm 1.72$} & $4.77 \pm 1.70$ \\
\hline Renin mRNA & \multicolumn{2}{|c|}{$3.58 \pm 0.85$} & $2.09 \pm 0.91$ & \multicolumn{2}{|c|}{$3.58 \pm 1.03^{*}$} & $4.10 \pm 1.08^{*}$ \\
\hline ACE protein & \multicolumn{2}{|c|}{$0.98 \pm 0.09$} & $0.94 \pm 0.17$ & \multicolumn{2}{|c|}{$1.11 \pm 0.30$} & $1.01 \pm 0.20$ \\
\hline ACE 2 protein & \multirow{2}{*}{\multicolumn{2}{|c|}{$1.78 \pm 0.24^{*}$}} & $2.79 \pm 0.45$ & \multicolumn{2}{|c|}{$1.93 \pm 0.61$} & $1.53 \pm 0.50^{*}$ \\
\hline Angiotensin II protein & \multirow{2}{*}{\multicolumn{2}{|c|}{$0.94 \pm 0.21$}} & $1.79 \pm 0.60$ & \multicolumn{2}{|c|}{$1.25 \pm 0.50$} & $1.17 \pm 0.73$ \\
\hline ATII receptor 1 protein & & & $2.05 \pm 0.40$ & \multirow{2}{*}{\multicolumn{2}{|c|}{$\begin{array}{l}1.30 \pm 0.13^{*} \\
1.25 \pm 0.41\end{array}$}} & $1.15 \pm 0.26^{*}$ \\
\hline \multirow[t]{4}{*}{ MCR protein } & \multicolumn{2}{|c|}{$0.74 \pm 0.18^{*}$} & $1.27 \pm 0.44$ & & & $1.16 \pm 0.23$ \\
\hline & \multicolumn{6}{|c|}{ eNOS KO } \\
\hline & \multicolumn{3}{|c|}{ Non-DM } & \multicolumn{3}{|c|}{ DM } \\
\hline & $\begin{array}{c}\text { No } \\
\text { treatment }\end{array}$ & Enalapril & Telmisartan & $\begin{array}{c}\text { No } \\
\text { treatment }\end{array}$ & Enalapril & Telmisartan \\
\hline Angiotensinogen mRNA & $1.0 \pm 0.26$ & $1.25 \pm 0.37$ & $1.95 \pm 1.17$ & $2.54 \pm 0.80^{\dagger}$ & $2.55 \pm 1.26$ & $1.56 \pm 0.52$ \\
\hline Renin MRNA & $1.0 \pm 0.48$ & $3.23 \pm 1.13^{\dagger}$ & $3.74 \pm 0.90^{\dagger}$ & $0.70 \pm 0.43$ & $2.41 \pm 0.88$ & $2.99 \pm 1.63^{\ddagger}$ \\
\hline ACE protein & $1.0 \pm 0.15$ & $0.95 \pm 0.23$ & $1.07 \pm 0.23$ & $0.75 \pm 0.13$ & $0.67 \pm 0.13$ & $0.67 \pm 0.17$ \\
\hline ACE 2 protein & $1.0 \pm 0.14$ & $0.80 \pm 0.17$ & $0.80 \pm 0.26$ & $1.82 \pm 0.30^{\dagger}$ & $2.33 \pm 0.44^{\S}$ & $2.32 \pm 0.42^{\text {वा }}$ \\
\hline Angiotensin II protein & $1.0 \pm 0.23$ & $1.14 \pm 0.39$ & $0.58 \pm 0.28$ & $0.86 \pm 0.26$ & $0.64 \pm 0.23$ & $0.53 \pm 0.29$ \\
\hline ATII receptor 1 protein & $1.0 \pm 0.11$ & $1.13 \pm 0.12$ & $1.19 \pm 0.11$ & $1.93 \pm 0.39^{\dagger}$ & $2.19 \pm 0.11^{\S}$ & $2.31 \pm 0.72^{\text {वा }}$ \\
\hline MCR protein & $1.0 \pm 0.12$ & $0.94 \pm 0.13$ & $1.19 \pm 0.35$ & $1.45 \pm 0.16^{\dagger}$ & $1.51 \pm 0.26^{\S}$ & $1.27 \pm 0.37$ \\
\hline
\end{tabular}

Data are means $\pm \mathrm{SD}(n=10)$. ATII, angiotensin II; MCR, mineralocorticoid receptor.

${ }^{*} P<0.05$ versus Wild DM no treatment.

${ }^{\dagger} P<0.05$ versus eNOSKO non-DM no treatment.

$\mp P<0.05$ versus eNOSKO DM no treatment.

$\S P<0.05$ versus eNOSKO non-DM enalapril.

IP $<0.05$ versus eNOSKO non-DM telmisartan. 


\section{Renin-Angiotensin-Aldosterone System}

Angiotensin II was identified by immunohistochemistry in the thin ascending limb, distal tubules, and collecting duct of non-DM wild-type mice. We have previously reported that angiotensin II staining with this antibody in the kidney correlates closely with tissue angiotensin II levels. ${ }^{17}$ The specificity was confirmed by the evidence that the immunoreactivity was abolished by pre-incubation with an excess amount of immunizing peptide (Figure 4, A-E). In wild-type mice, the diabetic condition tended to increase intrarenal angiotensin II level, which also tended to be reduced by RAS blockade (Table 2, Figure 4B). In eNOSKO mice, intrarenal angiotensin II staining tended to be lowered by diabetic condition, and to be further reduced by these treatments (Figure $4 \mathrm{~A}$, Table 2). Western blotting was consistent with the immunostaining results (Figure 4F).

Angiotensinogen mRNA expression was significantly increased by the diabetic condition in eNOSKO mice while this elevation was not prevented by either telmisartan or enalapril (Table 2). Renin mRNA expression was not induced in diabetic condition of both wild-type and eNOSKO mice, whereas it was significantly enhanced by RAS blockade (Table 2). In terms of ACE, protein expression in the kidney was identical between groups (Table 2, Figure 4). However, enalapril significantly reduced serum ACE activity in both nondiabetic and diabetic eNOSKO mice (Figure 4G). Similarly, serum ACE activity in enalapril-treated diabetic wild-type mice tended to be lowered compared with non-treated diabetic wild-type mice or telmisartan-treated diabetic wild-type mice, but the effect did not reach significance (Figure $4 \mathrm{G}$ ). These data provide evidence that the dose of enalapril given to diabetic eNOSKO mice sufficiently blocked ACE activity.

Angiotensin II receptor 1 (AT1R) was induced in diabetic condition in both wild-type and eNOSKO mice. Such up-regulation was significantly blocked by RAS blockade only in wild-type mice, but not in eNOSKO mice (Table 2). Similarly, ACE2 expression was significantly increased in diabetic condition of both wild-type and eNOSKO mice whereas such induction was prevented by telmisartan in wild-type, but not in eNOSKO mice (Table 2).

Serum aldosterone tended to be elevated in diabetic wild-type mice and to be lowered by enalapril and telmisartan treatment (although this did not reach significance). In diabetic eNOSKO mice serum aldosterone levels tended to be lower than that in wild-type diabetic mice, likely because $\mathrm{NO}$ deficiency is associated with impairment of sympathetic nervous system. ${ }^{18,19}$ However, in contrast, serum aldosterone tended to be paradoxically increased with RAS blockade in eNOSKO mice (Figure 4H). Mineralocorticoid receptor expression was induced by the diabetic condition in both wild-type and eNOSKO mice (Table 2).

\section{Spironolactone Treatment}

Given that the opposing patterns of aldosterone in response to RAS blockade in diabetic eNOSKO and
A

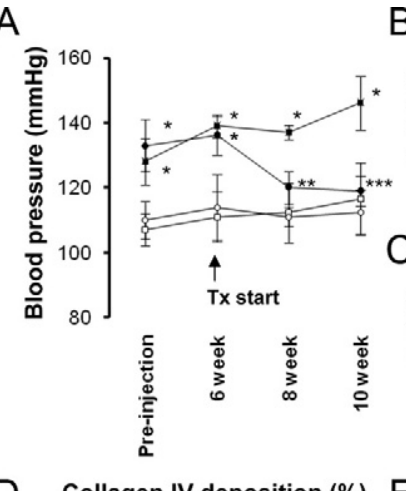

B Mesangial expansion (\%)
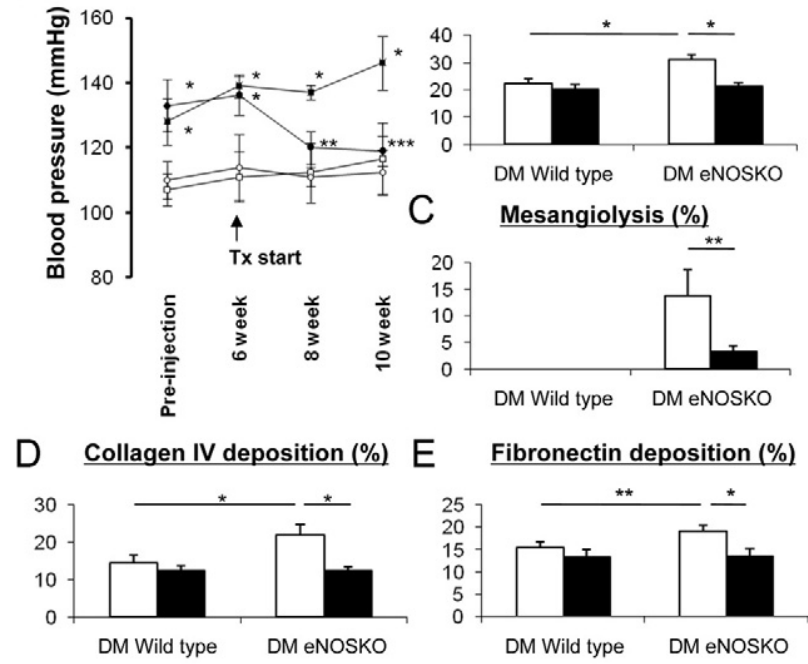

$\mathrm{F}$

F Tubular damage (\%)

G Osteopontin expression (\%)
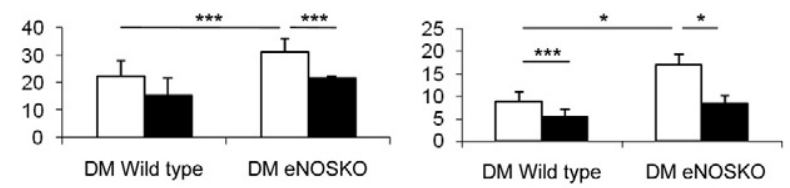

H Collagen III deposition (\%)

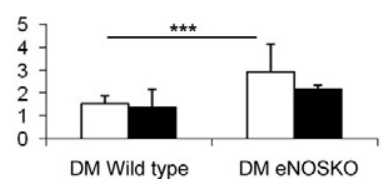

Figure 5. Spironolactone treatment in diabetic wild-type and eNOSKO mice. Time course of blood pressure is shown in A. Spironolactone was started at 6 weeks. Spironolactone significantly reduced blood pressure in DM eNOSKO mice at 8 and 10 weeks. Black square, DM eNOSKO mice with vehicle; black circle, DM eNOSKO mice with spironolactone; white square, DM wild-type mice with vehicle; white circle, DM wild-type mice with spironolactone. Data are shown as means and SD. ${ }^{*} P<0.001$ versus DM wild-type mice with vehicle; ${ }^{* *} P<0.05$ versus DM eNOSKO mice with vehicle; ${ }^{* * *} P<0.01$ versus $\mathrm{DM}$ eNOSKO mice with vehicle. $n=$ 12/each group. Quantitative analysis demonstrates that both mesangial expansion (B) and mesangiolysis (C) were decreased by spironolactone in DM eNOSKO mice. Similarly, glomerular collagen IV deposition (D) and FN deposition (E) were also reduced by spironolactone in DM eNOSKO mice. Tubulointerstitial injury, quantified either by PAS staining $(\mathbf{F})$, osteopontin expression $(\mathbf{G})$, and collagen III deposition $(\mathbf{H})$ were all less in spironolactone-treated DM eNOSKO mice compared with DM eNOSKO mice. White bar, vehicle; black bar, spironolactone. Data are shown as means and SD. ${ }^{*} P<0.001 ;{ }^{* * *} P<0.005 ;{ }^{* * *} P<0.05 . n=12 / \mathrm{each}$ group. Tx, no treatment.

wild-type mice, we evaluated the role of aldosterone in this model. We therefore conducted a second study in which we examined the effect of blocking aldosterone with spironolactone (Figure 5, A-H). In contrast to enalapril and telmisartan, spironolactone significantly reduced blood pressure and improved renal function (as evidenced by serum creatinine and urinary albumin excretion) in eNOSKO diabetic mice, although hyperglycemia was not improved by this treatment (Table 3). Similarly, spironolactone also blocked both glomerular damage and tubulointerstitial injury (Figure 6). In contrast no beneficial effect of spironolactone was observed on either blood pressure or renal injury in wild-type diabetic mice (Table 3). 
Table 3. General Characteristics at 10 Weeks in Diabetic Mice

\begin{tabular}{lccccc}
\hline & \multicolumn{2}{c}{ Wild type DM } & & \multicolumn{2}{c}{ eNOSKO DM } \\
\cline { 2 - 3 } & Vehicle & Spironolactone & & Vehicle & Spironolactone \\
\hline Body weight $(\mathrm{g})$ & $22.7 \pm 3.0$ & $23.2 \pm 3.4$ & & $18.4 \pm 2.1$ & $20.6 \pm 3.3$ \\
Blood sugar $(\mathrm{mg} / \mathrm{dl})$ & $301 \pm 62$ & $341 \pm 61$ & & $371 \pm 53$ & $354 \pm 67$ \\
Systolic BP $(\mathrm{mm} \mathrm{Hg})$ & $117 \pm 11$ & $113 \pm 7.0$ & & $146 \pm 8.4^{*}$ & $119 \pm 4.6^{\dagger}$ \\
Kidney/body weight $\left(10^{-3}\right)$ & $8.0 \pm 1.5$ & $7.0 \pm 2.0$ & & $8.0 \pm 0.1$ & $9.0 \pm 1.0$ \\
Serum creatinine $(\mathrm{mg} / \mathrm{dl})$ & $0.14 \pm 0.09$ & $0.09 \pm 0.03$ & & $0.13 \pm 0.06$ & $0.09 \pm 0.04$ \\
BUN (mg/dl) & $40.5 \pm 13$ & $35.0 \pm 4.0$ & & $48.3 \pm 7.2$ & $60.5 \pm 12^{\ddagger}$ \\
Urine albumin/creatinine & $0.068 \pm 0.071$ & $0.060 \pm 0.056$ & & $1.58 \pm 0.34^{*}$ & $0.64 \pm 0.065^{\S \pi}$ \\
\hline
\end{tabular}

Data are means $\pm \mathrm{SD}(n=10)$. BP, blood pressure.

${ }^{*} P<0.001$ versus wild $\mathrm{DM}$ vehicle.

${ }^{\dagger} P<0.01$ versus eNOSKO DM vehicle.

$\neq P<0.05$ versus Wild DM spironolactone.

$\$ P<0.001$ versus Wild DM spironolactone.

TI $P<0.001$ versus eNOSKO DM vehicle.

\section{Effect of High Dose of ACEl in Blood Pressure and Renal Injury of Diabetic eNOSKO Mice}

We next examined if higher dose of enalapril can lower blood pressure and slow renal disease progression in diabetic eNOSKO mice. As a control, one group of diabetic eNOSKO mice were treated with hydralazine, since hydralazine was shown to reduce blood pressure in this model. ${ }^{13}$ As shown in Figure 6, blood pressure was significantly lowered by hydralazine treatment after 12 weeks. In contrast, enalapril we did not lower blood pressure in diabetic eNOSKO mice even when the dose of enalapril was increased to $50 \mathrm{mg} / \mathrm{kg}$. In terms of renal injury, mesangial expansion in non-treated diabetic eNOSKO (35.5 \pm $3.8 \%)$ was significantly reduced by hydralazine (23.0 \pm $4.1 \%, P<0.01$ ) as previously reported. ${ }^{13}$ However, enalapril had no effect on mesangial expansion (34.8 $\pm 6.6 \%$, $P=$ N.S.). Similarly, glomerular collagen IV deposition was significantly reduced by hydralazine $(19 \pm 3.3 \%$ versus $25.4 \pm 2.8$ in non-treated diabetic eNOSKO, $P<0.05$ ), but not by enalapril $(27.1 \pm 2.6 \%, P=$ N.S. $)$. In terms of renal

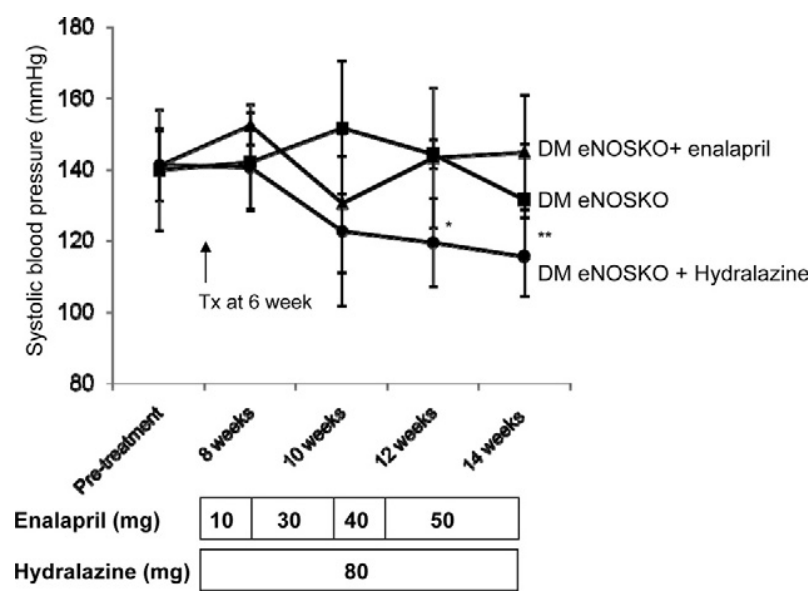

Figure 6. The effect of high dose enalapril on diabetic eNOSKO mice. Blood pressure in DM eNOSKO mice with/without enalapril or hydralazine treatment is shown (A). DM-eNOSKO mice was treated with/without enalapril or hydralazine treatment for 8 weeks. Despite increasing dose of enalapril, blood pressure was not lowered in DM eNOSKO mice. In contrast, hydralazine significantly lowered blood pressure. Black square, DM no treatment; black triangle, DM enalapril; black circle, DM hydralazine. $n=5$ /group. ${ }^{*} P<$ 0.01 versus DM non-treatment; ${ }^{* *} P<0.05$ versus DM enalapril. function, BUN in diabetic eNOSKO mice $(35.6 \pm 5.6 \mathrm{mg} / \mathrm{dl})$ tended to be higher than that in nondiabetic eNOSKO (29.3 \pm 3.0$)$. Enalapril treatment did not change BUN in this model $(32.5 \pm 2.0)$.

\section{Discussion}

The primary finding in this study was that both ACEI and ARBs had only partial benefits in slowing renal disease in diabetic eNOSKO mice. These studies contrast with the full renoprotection observed in wild-type diabetic mice. In contrast, aldosterone blockade provided excellent protection in the diabetic eNOSKO mouse, whereas minimal benefit was observed in diabetic wild-type mice.

An insufficient dose of enalapril is unlikely to be the cause of the ineffectiveness of enalapril in diabetic eNOSKO mice. Indeed, even when we used higher doses of enalapril (up to $50 \mathrm{mg} / \mathrm{kg} /$ day), neither blood pressure nor mesangial injury were blocked in the diabetic eNOSKO mouse (Figure 6) despite protection in wild-type diabetic mice. Furthermore, we documented that ACE activity was significantly suppressed by the dose of enalapril in diabetic eNOSKO mice (Figure 4).

While both ACE inhibitor and ARB had minor effects in improving renal injury, telmisartan was relatively more protective at reducing urinary albumin excretion and lowering blood pressure than enalapril. Interestingly, while intrarenal angiotensin II level was not increased by diabetic state in eNOSKO mice, AT1R expression was significantly induced. Hence, we cannot neglect the causal role for angiotensin II at this moment, and therefore, such favorable effect of telmisartan might be attributed to blocking angiotensin II. Other mechanisms, such as activation of peroxisome proliferator-activated receptor- $\gamma$ by $A R B,{ }^{20}$ might be also involved.

While the benefit from renin-angiotensin blockade is well accepted in the treatment of diabetic nephropathy, some studies have questioned the efficacy of this treatment, especially in subjects with type 2 diabetes and overt nephropathy. ${ }^{21-23}$ Recently Mauer et al documented that enalapril or losartan failed to slow the progression of renal disease in patient with type 1 diabetes despite being effective at preventing retinopathy. ${ }^{24} \mathrm{~A}$ 
mechanism for this failure of RAS blockades could be partially attributed to the development of "aldosterone breakthrough"25-27 While we could not document a significant change in aldosterone levels in our model, the difference in response to RAS inhibitors between diabetic wild-type and eNOSKO mice suggests that the lack of eNOS could have a role in this pathway. Clearly further studies are necessary to determine the role of endothelial NO in this pathway.

Recently, the causal role for renin in the development of diabetic nephropathy was demonstrated in experimental animal model. ${ }^{28-30}$ Consistently, large-scale clinical study documented the beneficial effect of renin inhibitor in patients with type 2 diabetes. ${ }^{31}$ While renin expression was reduced by diabetic condition in eNOSKO mice (as opposed to that in wild-type mice), in turn renin mRNA expression was up-regulated by enalapril or telmisartan treatment, indicating that a compensatory increase in renin expression might account for unfavorable effect of ACEI/ARB in this model. As such, combination of ACEI/ ARB with renin inhibitor might provide a better protection in diabetic eNOSKO mice.

In conclusion, both ACEI and ARB showed only partial renal protection in the diabetic eNOSKO mice as compared with full protection in diabetic wild-type mice. While it is possible that this may be due to inadequate suppression of the RAS, our studies suggest that the presence of severe deficiency in endothelial NO levels may have a role in blocking the response. In this model, aldosterone was found to be a major mediator of the renal injury. Future studies are necessary to better understand if there is a role for endothelial NO in modulating the aldosterone response to RAS blockade.

\section{Acknowledgments}

We thank Dr. Richard J. Johnson (University of Colorado Denver) for helpful advice and critical review of the manuscript.

\section{References}

1. Lewis EJ, Hunsicker LG, Bain RP, Rohde RD: The effect of angiotensin-converting-enzyme inhibition on diabetic nephropathy: The Collaborative Study Group. N Engl J Med 1993, 329:1456-1462

2. Brenner BM, Cooper ME, de Zeeuw D, Keane WF, Mitch WE, Parving HH, Remuzzi G, Snapinn SM, Zhang Z, Shahinfar S: Effects of losartan on renal and cardiovascular outcomes in patients with type 2 diabetes and nephropathy. N Engl J Med 2001, 345:861-869

3. Carter BL, Malone DC, Ellis SL, Dombrowski RC: Antihypertensive drug utilization in hypertensive veterans with complex medication profiles. J Clin Hypertens (Greenwich) 2000, 2:172-180

4. Scarsi KK, Bjornson DC: The use of ACE inhibitors as renoprotective agents in Medicaid patients with diabetes. Ann Pharmacother 2000, 34:1002-1006

5. Shiuchi T, Cui TX, Wu L, Nakagami H, Takeda-Matsubara Y, Iwai M, Horiuchi M: ACE inhibitor improves insulin resistance in diabetic mouse via bradykinin and NO. Hypertension 2002, 40:329-334

6. Chan WB, Chan NN, Lai CW, So WY, Lo MK, Lee KF, Chow CC, Metreweli C, Chan JC: Vascular defect beyond the endothelium in type II diabetic patients with overt nephropathy and moderate renal insufficiency. Kidney Int 2006, 70:711-716

7. Jawa A, Nachimuthu S, Pendergrass M, Asnani S, Fonseca V: Im- paired vascular reactivity in African-American patients with type 2 diabetes mellitus and microalbuminuria or proteinuria despite angiotensin-converting enzyme inhibitor therapy. J Clin Endocrinol Metab 2006, 91:31-35

8. Papaioannou GI, Seip RL, Grey NJ, Katten D, Taylor A, Inzucchi SE, Young LH, Chyun DA, Davey JA, Wackers FJ, Iskandrian AE, Ratner RE, Robinson EC, Carolan S, Engel S, Heller GV: Brachial artery reactivity in asymptomatic patients with type 2 diabetes mellitus and microalbuminuria (from the Detection of Ischemia in Asymptomatic Diabetics-Brachial Artery Reactivity Study). Am J Cardiol 2004, 94:294-299

9. Yilmaz MI, Saglam M, Qureshi AR, Carrero JJ, Caglar K, Eyileten T, Sonmez A, Cakir E, Oguz Y, Vural A, Yenicesu M, Stenvinkel P. Lindholm B, Axelsson J: Endothelial dysfunction in type-2 diabetics with early diabetic nephropathy is associated with low circulating adiponectin. Nephrol Dial Transplant 2008, 23:1621-1627

10. Kanetsuna Y, Takahashi K, Nagata M, Gannon MA, Breyer MD, Harris RC, Takahashi T: Deficiency of endothelial nitric-oxide synthase confers susceptibility to diabetic nephropathy in nephropathy-resistant inbred mice. Am J Pathol 2007, 170:1473-1484

11. Nakagawa T, Sato W, Glushakova O, Heinig M, Clarke T, CampbellThompson M, Yuzawa Y, Atkinson M, Johnson RJ, Croker B: Diabetic eNOS knockout mice develop advanced diabetic nephropathy. J Am Soc Nephrol 2007, 18:539-550

12. Zhao HJ, Wang S, Cheng H, Zhang MZ, Takahashi T, Fogo AB, Breyer MD, Harris RC: Endothelial nitric oxide synthase deficiency produces accelerated nephropathy in diabetic mice. J Am Soc Nephrol 2006, 17:2664-2669

13. Kosugi $T$, Heinig M, Nakayama $T$, Connor $T$, Yuzawa $Y$, Li Q, Hauswirth WW, Grant MB, Croker BP, Campbell-Thompson M, Zhang L, Atkinson MA, Segal MS, Nakagawa T: Lowering blood pressure blocks mesangiolysis and mesangial nodules, but not tubulointerstitial injury, in diabetic eNOS knockout mice. Am J Pathol 2009, 174:1221-1229

14. Breyer MD, Bottinger E, Brosius FC, 3rd, Coffman TM, Harris RC, Heilig CW, Sharma K: Mouse models of diabetic nephropathy. J Am Soc Nephrol 2005, 16:27-45

15. Kosugi T, Yuzawa Y, Sato W, Arata-Kawai H, Suzuki N, Kato N, Matsuo S, Kadomatsu K: Midkine is involved in tubulointerstitial inflammation associated with diabetic nephropathy. Lab Invest 2007, 87:903-913

16. Nakagawa T, Lan HY, Zhu HJ, Kang DH, Schreiner GF, Johnson RJ: Differential regulation of VEGF by TGF-beta and hypoxia in rat proximal tubular cells. Am J Physiol Renal Physiol 2004, 287:F658-F664

17. Franco M, Martinez F, Quiroz Y, Galicia O, Bautista R, Johnson RJ, Rodriguez-Iturbe B: Renal angiotensin II concentration and interstitial infiltration of immune cells are correlated with blood pressure levels in salt-sensitive hypertension. Am J Physiol Regul Integr Comp Physiol 2007, 293:R251-R256

18. Scrogin KE, Veelken R, Luft FC: Sympathetic baroreceptor responses after chronic NG-nitro-L-arginine methyl ester treatment in conscious rats. Hypertension 1994, 23:982-986

19. Angell-James JE, George MJ, Peters CJ: Baroreflex sensitivity in rabbits during the development of experimental renal hypertension and medial sclerosis. Clin Exp Hypertens 1980, 2:321-340

20. Benson SC, Pershadsingh HA, Ho Cl, Chittiboyina A, Desai P, Pravenec M, Qi N, Wang J, Avery MA, Kurtz TW: Identification of telmisartan as a unique angiotensin II receptor antagonist with selective PPARgammamodulating activity. Hypertension 2004, 43:993-1002

21. Perkins BA, Ficociello LH, Silva KH, Finkelstein DM, Warram JH, Krolewski AS: Regression of microalbuminuria in type 1 diabetes. N Engl J Med 2003, 348:2285-2293

22. Suissa S, Hutchinson T, Brophy JM, Kezouh A: ACE-inhibitor use and the long-term risk of renal failure in diabetes. Kidney Int 2006, 69:913-919

23. Ruggenenti P, Mosconi L, Sangalli F, Casiraghi F, Gambara V, Remuzzi G, Remuzzi A: Glomerular size-selective dysfunction in NIDDM is not ameliorated by ACE inhibition or by calcium channel blockade. Kidney Int 1999, 55:984-994

24. Mauer M, Zinman B, Gardiner R, Suissa S, Sinaiko A, Strand T, Drummond K, Donnelly S, Goodyer P, Gubler MC, Klein R: Renal and 
retinal effects of enalapril and losartan in type 1 diabetes. $\mathrm{N}$ Engl J Med 2009, 361:40-51

25. Bomback AS, Klemmer PJ: The incidence and implications of aldosterone breakthrough. Nat Clin Pract Nephrol 2007, 3:486-492

26. Hollenberg NK: Aldosterone in the development and progression of renal injury. Kidney Int 2004, 66:1-9

27. Schjoedt KJ, Andersen S, Rossing P, Tarnow L, Parving HH: Aldosterone escape during blockade of the renin-angiotensin-aldosterone system in diabetic nephropathy is associated with enhanced decline in glomerular filtration rate. Diabetologia 2004, 47:1936-1939

28. Ichihara A, Hayashi M, Kaneshiro Y, Suzuki F, Nakagawa T, Tada Y, Koura $Y$, Nishiyama A, Okada H, Uddin MN, Nabi AH, Ishida $Y$, Inagami T, Saruta T: Inhibition of diabetic nephropathy by a decoy peptide corresponding to the "handle" region for nonproteolytic activation of prorenin. J Clin Invest 2004, 114:1128-1135

29. Ichihara A, Suzuki F, Nakagawa T, Kaneshiro Y, Takemitsu T, Sakoda M, Nabi AH, Nishiyama A, Sugaya T, Hayashi M, Inagami T: Prorenin receptor blockade inhibits development of glomerulosclerosis in diabetic angiotensin II type 1a receptor-deficient mice. J Am Soc Nephrol 2006, 17:1950-1961

30. Kelly DJ, Zhang Y, Moe G, Naik G, Gilbert RE: Aliskiren, a novel renin inhibitor, is renoprotective in a model of advanced diabetic nephropathy in rats. Diabetologia 2007, 50:2398-2404

31. Parving HH, Persson F, Lewis JB, Lewis EJ, Hollenberg NK: Aliskiren combined with losartan in type 2 diabetes and nephropathy. N Engl J Med 2008, 358:2433-2446 